\title{
Intoxicação por Ipomoea asarifolia em bovinos e ovinos no Rio Grande do Norte ${ }^{1}$
}

\author{
Fabricio K. de L. Carvalho ${ }^{2 *}$, Antônio F.M. Dantas², Franklin Riet-Correa², \\ João P.S. Pires ${ }^{2}$ e Fabrício O.R. Silva ${ }^{2}$
}

\begin{abstract}
Carvalho F.K.L., Dantas A.F.M., Riet-Correa F., Pires J.P.S. \& Silva F.O.R. 2014. [Ipomoea asarifolia poisoning in cattle in Rio Grande do Norte.] Intoxicação por Ipomoea asarifolia em bovinos e ovinos no Rio Grande do Norte. Pesquisa Veterinária Brasileira 34(11):10731076. Hospital Veterinário, Laboratório de Patologia Animal, Centro de Saúde e Tecnologia Rural, Universidade Federal de Campina Grande, Campus de Patos, Av. Universitária s/n, Bairro Santa Cecília, Patos, PB 58708-110, Brazil. E-mail: fabriciokleber@hotmail.com

Ipomoea asarifolia is one of the main poisonous plants in the North and Northeast of Brazil. The poisoning occurs during the dry season when there is shortage of forage, and is more common in sheep; however spontaneous cases are also reported in goats, cattle and buffaloes. This paper reports 18 outbreaks of poisoning in cattle by I. asarifolia which occurred from August 2012 to February 2013 in the state of Rio Grande do Norte. From a total of 1,704 cattle, $202(11.8 \%)$ were affected and 34 (2\%) died. On six farms sheep were also affected. Poisoning outbreaks were also observed in lambs and calves that had no access to the pastures but suckled milk from cows and ewes that had ingested I. asarifolia.
\end{abstract}

INDEX TERMS: Poisonous plants, Ipomoea asarifolia, Covolvulaceae, intention tremors, tremorgenic toxins, plant poisoning, cattle, sheep.

RESUMO.- Ipomoea asarifolia é uma das principais plantas tóxicas para ruminantes nas regiões Norte e Nordeste. A intoxicação ocorre na época das secas quando há escassez de forragem e é mais frequente em ovinos do que em outras espécies, porem casos espontâneos também são relatados em caprinos, bovinos e búfalos. Este trabalho relata a ocorrência de 18 surtos de intoxicação em bovinos por $I$. asarifolia que ocorreram de agosto de 2012 a fevereiro de 2013 no estado do Rio Grande Norte. De um total de 1704 bovinos, $202(11,8 \%)$ adoeceram e $34(2 \%)$ morreram. Em seis propriedades onde havia ovinos estes também se intoxicaram. Foram observados também sinais clínicos em bezerros e cordeiros confinados, sem acesso às pastagens, que se intoxicaram pela ingestão do leite das mães que ingeriam I. asarifolia a pasto.

TERMOS DE INDEXAÇÃO: Plantas tóxicas, Ipomoea asarifolia, Co-

\footnotetext{
${ }^{1}$ Recebido em 2 de julho de 2014.

Aceito para publicação em 6 de outubro de 2014.

Parte da Dissertação de Mestrado do primeiro autor, Programa de Pós-Graduação em Medicina Veterinária, Universidade Federal de Campina Grande (UFCG), Av. Universitária s/n, Bairro Santa Cecília, Patos, PB 58708-110, Brasil.

${ }^{2}$ Hospital Veterinário, Centro de Saúde e Tecnologia Rural (CSTR), UFGC, Patos, PB 58708-110. *Autor para correspondência: dantas.af@uol.com.br
}

volvulaceae, tremores de intenção, toxinas tremorgênicas, intoxicaçãopor plantas, bovinos, ovinos.

\section{INTRODUÇÃO}

A intoxicação por Ipomoea asarifolia ocorre em ruminantes nas regiões Norte e Nordeste na época das secas quando há escassez de forragem (Medeiros et al. 2003, Barbosa et al. 2005, Guedes et al. 2007, Tortelli et al. 2008). No semiárido I. asarifolia é encontrada, preferencialmente, as margens de lagos, rios, açudes e praias, em áreas abandonadas ou nas margens de estradas. A intoxicação é mais frequente em ovinos do que em outras espécies, afetando principalmente ovinos jovens e lactentes (Araújo et al. 2008, Tortelli et al. 2008, Pessoa et al. 2013), porém casos espontâneos também são relatados em caprinos no nordeste (Medeiros et al., 2003) e em bovinos e búfalos na Ilha de Marajó (Barbosa et al. 2005, Tortelli et al. 2008). Em entrevistas realizadas com produtores do Rio Grande do Norte, I. asarifolia foi mencionada como a principal planta tóxica para bovinos (Silva et al. 2006). Experimentalmente bovinos e búfalos são mais susceptíveis que caprinos e ovinos; Dobereiner et al. (1960) observaram que os sinais clínicos nos bovinos começam entre 2 e 4 dias de ingestão da planta, enquanto que nos ovinos e caprinos aparecem após algumas semanas de ingestão. Barbosa et al. (2005) comprovaram que 
experimentalmente os búfalos são tão sensíveis quanto os bovinos à intoxicação por I. asarifolia.

Apesar de não ser conhecido o principio ativo da I. asarifolia, os sinais clínicos são semelhantes aos de toxinas tremorgênicas, caraterizados por tremores musculares, inicialmente de cabeça e pescoço que posteriormente se generalizam por todo o corpo, culminando com perda de equilíbrio seguido de quedas (Medeiros et al. 2003). Também foi determinado em camundongos que o principio ativo ou um metabolito do mesmo tem a capacidade de passar pelo leite intoxicando os filhotes lactentes sem que as mães apresentem sinais (Lopes 2013).

A intoxicação por I. asarifolia é a intoxicação mais frequente em ruminantes no semiárido (Silva et al. 2006), porém não há publicações descrevendo a intoxicação espontânea em bovinos na região Nordeste, portanto desconhecem-se os aspectos epidemiológicos da doença nesta espécie, importantes para o controle e profilaxia da mesma. Objetivou-se neste trabalho relatar os dados epidemiológicos dos surtos de intoxicação natural por I. asarifolia ocorridos entre agosto de 2012 e fevereiro de 2013 na microrregião do Seridó Oriental no estado do Rio Grande do Norte.

\section{MATERIAL E MÉTODOS}

O estudo foi realizado nos municípios de Acari, Carnaúba dos Dantas, Cruzeta, Currais Novos, Equador, Jardim do Seridó, Ouro Branco, Parelhas, Santana do Seridó e São José do Seridó. A re- gião, localizada no Centro-sul do Rio Grande do Norte, abrange uma área territorial de $3.825,73 \mathrm{~km}^{2}$, equivalente a $7,24 \%$ de todo o território do Estado (Bezerra Jr \& Silva 2007).

Para a realização do estudo, foram visitadas 18 fazendas e aplicados questionários aos produtores nos meses de janeiro e fevereiro de 2013. Nesse formulário, além dos dados do proprietário, questionou-se sobre a presença da planta na fazenda e ocorrência, morbidade e mortalidade da intoxicação, nas diferentes espécies, em diferentes anos; assim como a faixa etária dos animais intoxicados, o período da intoxicação e os sinais clínicos e evolução da doença.

Foram coletados os dados epidemiológicos e realizada a avaliação clínica de animais intoxicados. Foram utilizados dados pluviométricos das cidades de Acari, Carnaúba dos Dantas, Currais Novos, das estações meteorológicas que fornecem serviço à Empresa de Pesquisa e Agropecuária do Rio Grande do Norte (Emparn 2013).

\section{RESULTADOS}

Foram relatados 18 surtos de intoxicação por Ipomoea asarifolia em bovinos. Nesses surtos de um total de 1704 bovinos adoeceram 202 (11,8\%) e morreram 34 (2\%). Não foram realizadas necropsias, pois no período das visitas os animais doentes já estavam se recuperando. 0 sistema de criação era de pastejo extensivo ou semi-extensivo, em áreas de caatinga ou áreas desmatadas com substituição das espécies arbóreas por invasoras e forrageiras nativas. Todas as áreas estavam invadidas por I. asarifolia.

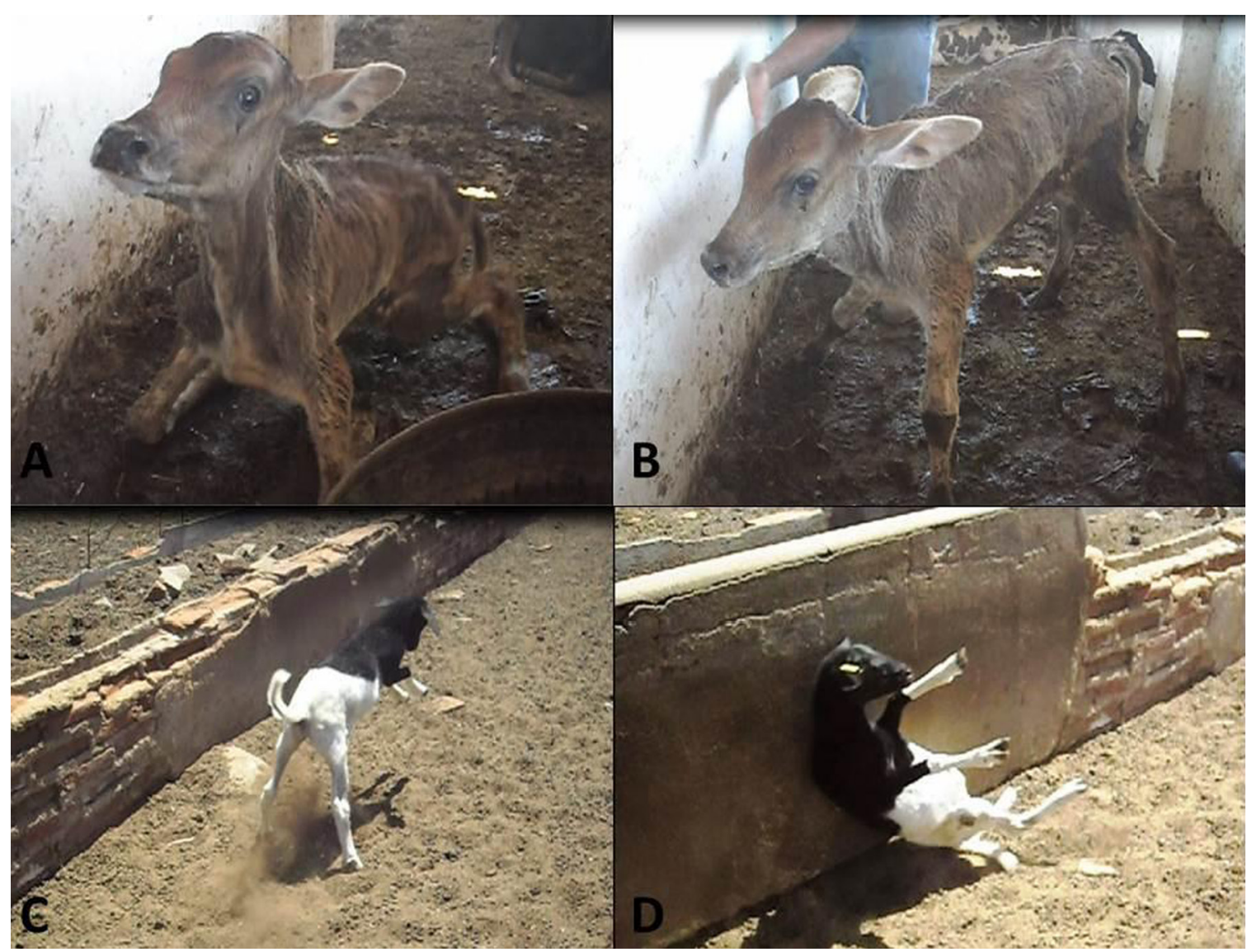

Fig.1. Animais intoxicados pelo leite de mães que ingeriam Ipomoea asarifolia no pasto. (A) Bezerro em decúbito esternal com dificuldade para se levantar. (B) Bezerro em postura de base ampla. (C) Cordeiro apresentando membros pélvicos enrijecidos durante a caminhada. (D) Cordeiro caindo em posição inusual após tentar se locomover. 
Em todas as propriedades visitadas, os produtores relataram que a doença tinha ocorrido em anos anteriores, em períodos de secas prolongadas quando sempre observavam bovinos apresentando sinais clínicos compatíveis com aqueles de intoxicação por I. asarifolia, apresentando morbidade variável e baixa mortalidade. As fazendas onde ocorreram os surtos estão localizadas na região semiárida, caracterizada por temperatura média de $26^{\circ} \mathrm{C}$, umidade relativa de aproximadamente 50\%, insolação de 2800 horas ao ano, evaporação de $2000 \mathrm{~mm} / \mathrm{ano}$, chuvas de 350-800 $\mathrm{mm}$ /ano e com um longo período seco, de Maio a Junho e Fevereiro a Março (Moura et al. 2007).

Em seis das propriedades estudadas, além dos bovinos, havia ovinos que ingeriam a planta e também apresentavam sinais da intoxicação. As intoxicações foram observadas em animais de todas as faixas etárias, incluindo bezerros e cordeiros lactentes com menos de dois meses de idade. Nos bovinos intoxicados eram observados principalmente tremores, ataxia e andar cambaleante. Quando parados foram observados tremores por todo o corpo, principalmente da cabeça e pescoço, e aumento da base de sustentação caracterizado pela abertura dos membros. As orelhas permaneciam em posição de alerta. Quando os animais eram agitados, os tremores se intensificavam podendo ocorrer quedas em posições inusuais e com dificuldade para se levantar, porém quando em repouso se levantavam espontaneamente em alguns minutos. Segundo os produtores, os bovinos apresentam recuperação dos sinais clínicos mais lentos do que os ovinos. Em geral os bovinos se recuperavam em 30 a 40 dias, mas aqueles que passavam mais tempo em decúbito esternal ou lateral, demoravam até três meses para se recuperar. Os proprietários informaram que os ovinos ingerem a planta com maior frequência do que os bovinos; no entanto os bovinos se intoxicam mais rapidamente após iniciar a ingestão.

No período das visitas às propriedades observaram-se cordeiros e bezerros lactentes intoxicados. Esses animais permaneciam nos currais enquanto suas mães saiam para pastejar. Eram alimentados com leite materno e capim que era fornecido no cocho. Os bezerros apresentavam sinais semelhantes aos dos bovinos adultos, e quando ficavam em estação permaneciam com membros afastados assumindo posição de cavalete. Ao serem movimentados apresentavam severa ataxia, com dismetria e hipermetria com os membros rígidos e com quedas em posições inusuais (Fig.1).

Os produtores entrevistados relataram que os bovinos só começam a ingerir a planta quando não existe praticamente nada mais para comer. De 2012 até o início do ano de 2013 as chuvas foram escassas; no município de Acari choveu apenas nos meses de janeiro (18,6mm) e fevereiro (54,6mm) de 2012, no município de Carnaúba dos Dantas apenas nos meses de fevereiro de 2012 (2,7mm) e 2013 (5,4mm), e no município de Currais Novos nos meses de janeiro $(8 \mathrm{~mm})$, fevereiro $(38,1 \mathrm{~mm})$, junho $(5,8 \mathrm{~mm})$ e julho (6,5mm) de 2012 e fevereiro de 2013 (2,2mm) (Fig.2). A partir do mês de julho de 2012 começaram a aparecer casos de intoxicação em ovinos, e logo depois, já no final do mês de agosto, vários casos de bovinos já tinham sido constatados. Nos casos de intoxicação por I. asarifolia o principal fator que predispõe aos surtos é a fome, pois essa planta não é palatável e os animais só começam a ingeri-la quando há extrema carência de forragem no pasto.

\section{DISCUSSÃO E CONCLUSÃO}

As intoxicações por Ipomoea asarifolia em bovinos é de alta relevância para a região do Rio Grande do Norte, visto que a agropecuária da região é direcionada a bovinocultura; em censo agropecuário realizado no ano de 2006 observou-se que o rebanho bovino era de 907.185 cabeças, maior do que a soma de todas as outras criações de animais de produção, sendo observados 410.019 ovinos, 273.562 ca-

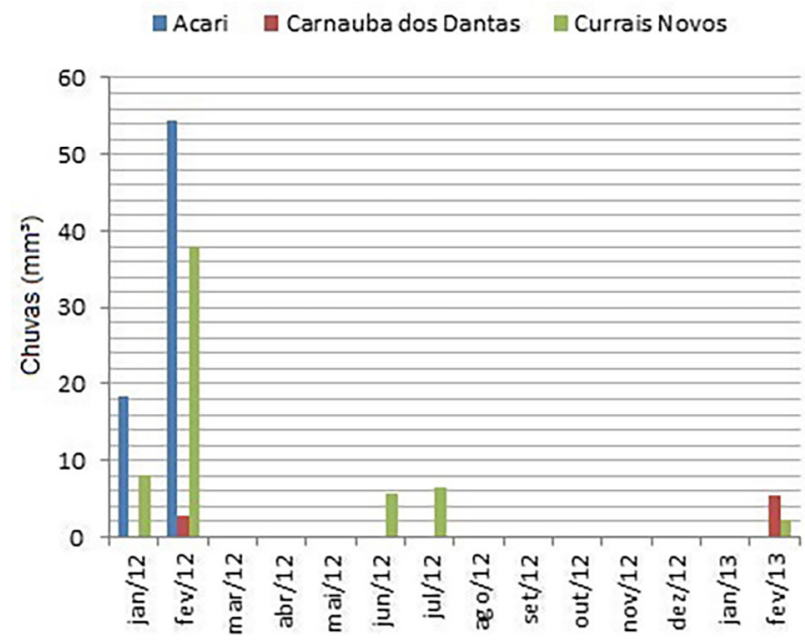

Análise das Chuvas Acumuladas (Quantis) - Ano: 2012 e 2013 Microrregião: Seridó Oriental Período: 01/01/2012 a 31/02/2013

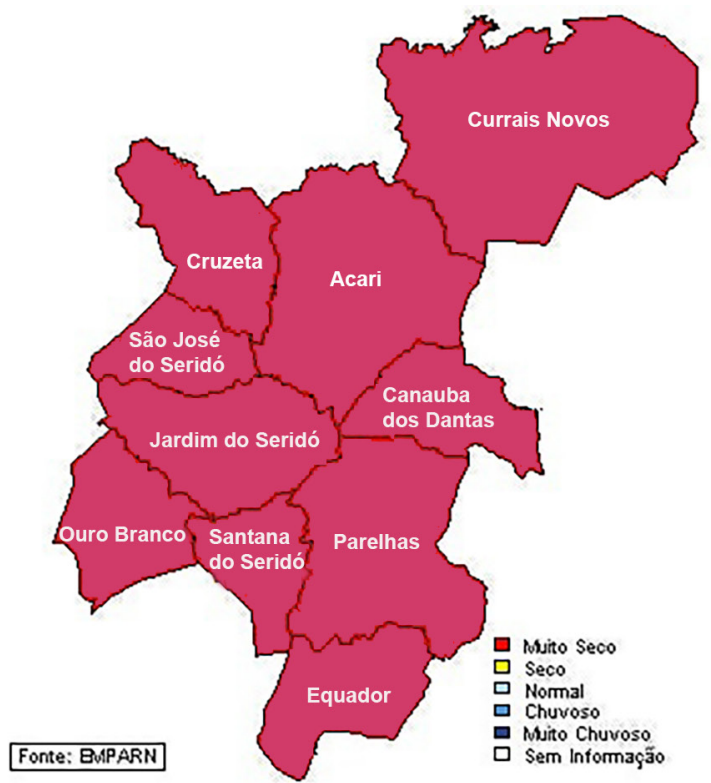

Fig.2. Dados pluviométricos obtidos das estações meteorológicas das cidades de Acari, Carnaúba dos Dantas, Currais Novos. 
prinos, 78.331 suínos e 67.735 equídeos (equinos, muares e asininos) (IBGE 2006).

A observação de sinais clínicos em bezerros e cordeiros lactentes, que permaneciam confinados enquanto suas mães saiam para pastejar em áreas onde existia a planta, sugere que o principio ativo da I. asarifolia é eliminado pelo leite. Freitas et al. (2011) relataram dois surtos de intoxicação por I. asarifolia em cordeiros e cabritos lactentes confinados que não ingeriam a planta, enquanto sua mães a ingeriam no campo. Porém, experimentalmente, Araújo et al. (2008) e Freitas et al. (2011) não conseguiram reproduzir a intoxicação em cordeiros e cabritos lactentes, confinados, filhos de ovelhas e cabras ingerindo I. asarifolia. As ovelhas ingeriram doses que variaram de 2,5 a $10 \mathrm{~g} / \mathrm{kg} / \mathrm{pv}$ por até 60 dias consecutivos, as cabras ingeriram $15 \mathrm{~g} / \mathrm{kg} / \mathrm{pv}$ durante 30 dias consecutivos. Porém, em experimento com camundongos fêmeas, em lactação, que ingeriam $20 \%$ ou $30 \%$ de I. asarifolia na ração observou-se que todas as proles apresentaram tremores de 2 a 4 dias após o nascimento (Lopes 2013).

Os dados epidemiológicos observados nesse trabalho demostram a importância da intoxicação por I. asarifolia em bovinos na microrregião do Seridó Oriental no estado do Rio Grande do Norte. As intoxicações são relatadas anualmente pelos produtores, que normalmente retiram os animais das pastagens evitando maiores perdas econômicas. Porém com a estiagem prolongada dos anos de 2012 e 2013, provocando uma severa escassez de alimento, os produtores ficaram sem alternativas de controle o que levou à alta prevalência da enfermidade e a morte de muitos animais.

Agradecimento.- Este trabalho foi financiado pelo Instituto Nacional de Ciência e Tecnologia para o Controle de Intoxicações de Plantas, CNPq (Processo 573534/2008-0).

\section{REFERÊNCIAS}

Araújo J.A.S., Riet-Correa F., Medeiros R.M.T., Soares M.P., Oliveira D.M. \& Carvalho F.K.L. 2008. Intoxicação experimental por Ipomoea asarifolia (Convolvulaceae) em caprinos e ovinos. Pesq. Vet. Bras. 28(10):488-494.

Barbosa J.D., Oliveira C.M.C., Duarte M.D., Peixoto P.V. \& Tokarnia C.H. 2005.
Intoxicações experimental e natural por Ipomoea asarifolia (Convolvulaceae) em búfalos e outros ruminantes. Pesq. Vet. Bras. 25(4):231-234.

Bezerra Júnior J.G.O. \& Silva N.M. 2007. Caracterização geoambiental da microrregião do Seridó Oriental do Rio Grande do Norte. Holos 23(2):78-91.

Döbereiner J., Tokarnia C.H. \& Canella C.F.C. 1960. Intoxicação experimental pela "salsa" (Ipomoea asarifolia R. et Schult.) em ruminantes. Arqs Inst. Biol. Animal, Rio de J., 3:39-57.

Emparn 2013. Empresa de Pesquisa Agropecuária do Rio Grande do Norte. Disponível em <http://www.emparn.rn.gov.br/contentproducao/aplicacao/emparn/principal/enviados/index.asp? Acessado em 15 jul. 2013.

Freitas FJ.C., Lima J.M., Gameleira J.S., Costa A.L.F., Câmara A.C.L. \& Soto-Blanco B. 2011. Surtos de intoxicação por Ipomoea asarifolia (salsa) em cordeiros e Cabritos lactentes. Vet. Zootec., Botucatu, 18(Supl.3):548551.

Guedes K.M.R., Riet-Correa F., Dantas A.F.M., Simôes S.V.D., Miranda Neto E.G., Nobre V.M.T. \& Medeiros R.M.T. 2007. Doenças do sistema nervoso central em caprinos e ovinos no semi-árido. Pesq. Vet. Bras. 27(1):29-38.

IBGE 2006. Censo Agropecuário. Estado do Rio Grande do Norte Disponível em <http://www.ibge.gov.br/estadosat/temas.php?sigla=rn\&tema =censoagro? Acessado em 12 mar. 2014.

Lopes J.R.G. 2013. Efeitos da administração de diferentes concentrações de folhas de Ipomoea asarifolia na ração de camundongos e eliminação da toxina tremogênica pelo leite. Dissertação de Mestrado, Universidade Federal de Campina Grande, PB. 40p.

Medeiros R.M.T., Barbosa R.C., Riet-Correa F., Lima E.F., Tabosa I.M., Barros S.S., Gardner D.R. \& Molyneux R.J. 2003. Tremorgenic syndrome in goats caused by Ipomoea asarifolia in northeastern Brasil. Toxicon 41:993- 935.

Moura M.S.B., Galvincio J.D., Brito L.T.L., Souza L.S.B., Silva Sá I.I. \& Silva T.G.F. 2007. Clima e água de chuvas no semi-árido, p.35-59. In: Brito L.T.L., Moura M.S.B. \& Gama G.F.B. (Eds). Potencialidades da água de chava no semi-árido brasileiro. Embrapa Semi-Árido, Petrolina, PE. Embrapa Semiárido, 181p.

Pessoa C.R.M., Medeiros R.M.T. \& Riet-Correa F. 2013. Importância econômica, epidemiologia e controle das intoxicações por plantas no Brasil. Pesq. Vet. Bras. 33(6):752-758.

Silva D.M., Riet-Correa F., Medeiros R.M.T. \& Oliveira O.F. 2006. Plantas tóxicas para ruminantes e equídeos no Seridó Ocidental e Oriental do Rio Grande do Norte. Pesq. Vet. Bras. 33(6):752-758.

Tortelli P.F., Barbosa J.D., Oliveira C.M.C., Duarte M.D., Cerqueira V.D., Oliveira C.A., Riet-Correa F. \& Riet-Correa G. 2008. Intoxicação por Ipomoea asarifolia em ovinos e bovinos na Ilha de Marajó. Pesq. Vet. Bras. 28(12):622-626. 